\title{
Heat exposure tests on various types of fibre mortar
}

\author{
Mohammed Ezziane*, ** - Laurent Molez** \\ Raoul Jauberthie** — Damien Rangeard**
}

\author{
* Département Génie Civil, Laboratoire LMPC \\ Université de Mostaganem, 27000, Algérie \\ Ezzmed44@yahoo.fr ; Mohammed.Ezziane@insa-rennes.fr \\ ** Laboratoire Génie Civil et Génie Mécanique \\ INSA - Université Européenne de Bretagne \\ 20, avenue des Buttes de Coësmes, CS 70839, F35708 Rennes cedex, France \\ \{Laurent.Molez, Raoul.Jauberthie,Damien.Rangeard\}@insa-rennes.fr
}

ABSTRACT. The advantage of steel fibres in cement based materials vis-à-vis mechanical reinforcement is widely recognized in the field of construction. This paper considers the behaviour of materials under extreme conditions in terms of temperature (e.g. fire). To this end, a comparison is made of the mechanical behaviour of mortars reinforced with steel fibres, polypropylene fibres and a hybrid fibre combination. These mortars are subjected to various heat exposures and then tested mechanically. Protection mechanisms of steel fibres and polypropylene are analyzed. SEM observations of steel fibres show oxidation at high temperatures; this oxidation impairs the protective effect of steel fibres.

RÉSUMÉ. L'intérêt des fibres d'acier dans les matériaux cimentaires vis-à-vis du renforcement mécanique est reconnu dans le domaine de la construction. Nous nous intéressons ici au comportement de ces matériaux dans des conditions extrêmes du point de vue de la température (par exemple un incendie). Pour cela, nous comparons le comportement mécanique de mortiers renforcés avec des fibres d'acier, des fibres de polypropylène et des mortiers hybrides. Ces mortiers ont été soumis à divers traitement thermique puis testés mécaniquement. Les mécanismes de protection des fibres d'acier et de polypropylène sont analysés. Des observations au MEB des fibres d'acier mettent en évidence une oxydation aux hautes températures. Cette oxydation compromet l'effet protecteur des fibres d'acier.

KEYWORDS: fibre reinforced mortar, steel fibres, PP fibres, mechanical behaviour, fire resistance.

MOTS-CLÉS : mortier fibré, fibres d'acier, fibres de polypropylène, comportement mécanique, incendie.

DOI:10.3166/EJECE.15.715-726 ㅇ 2011 Lavoisier, Paris

EJECE. Volume 15 - No. 5/2011, pages 715 to 726 


\section{Introduction}

The use of steel fibres in a standard mortar provides increased strength and ductility at room temperature. During exposure to high temperatures, a cementitious material reinforced with steel fibres undergoes deterioration to a greater or lesser extent. Heat induces various changes of material properties; in particular changes to the micro-structure which are accompanied by loss of strength and mass (Serdar et al., 2008; Fu et al., 2004). The aim of this study is to test the mechanical influence of different fibre types after exposure to high temperatures.

\section{Experimental programme}

\subsection{Sample preparation and conservation}

Four types of mortar were prepared: normalised 'standard' mortar, steel fibre mortar, polypropylene fibre mortar and finally a hybrid mortar (equal proportions of metal fibres and polypropylene fibres). Cement CEM I $52.5 \mathrm{R}$ was used for the preparation of the four mortar types. The water cement ratio $(w / c)$ for the mixes was 0.5 and the sand cement ratio $(\mathrm{s} / \mathrm{c})$ was 3 . For the three mortars with fibre addition, the fibre content was $0.58 \%$ by volume; this allowed an acceptable workability without the need to use a superplasticizer. All mixes were prepared using the same protocol. Water was added to cement and mixed to obtain a homogeneous paste; sand then gradually added to the paste and mixed until homogeneous. In the case of the fibre mortars, steel fibres were added at the final stage and dispersed manually. The constituents were mixed for two minutes after the introduction of the fibres.

The specimens were then stored in a wet room $\left(20^{\circ} \mathrm{C}, 95 \% \mathrm{RH}\right)$ for $24 \mathrm{~h}$ and then stored in dry room $\left(20^{\circ} \mathrm{C}, 50 \% \mathrm{RH}\right)$ up to an age of 28 days. Under these conditions, a significant portion of free water in the cement matrix had evaporated (Andrade et al., 1999).

\subsection{Heat exposure}

Mechanical properties are influenced notably by the sample size and the rate of temperature rise. The temperature gradient inside the samples can induce microcracking by virtue of thermal expansion. However, it is the temperature attained and the duration of exposure that are important in the chemical and mineralogical transformations of the material (Castellote et al., 2004; Georgali et al., 205). Two types of heat exposure were used in the study; exposure to heat in the oven, rapid heating due to exposure to a flame. 


\subsubsection{Heat exposure in an oven}

The heat exposure was carried out on prismatic samples $4 \times 4 \times 16 \mathrm{~cm}^{3}$. The exposure temperatures were set at $400^{\circ} \mathrm{C}, 500^{\circ} \mathrm{C}, 600^{\circ} \mathrm{C}, 700^{\circ} \mathrm{C}, 800^{\circ} \mathrm{C}$ and $1000^{\circ} \mathrm{C}$; the exposure time, at a constant temperature, was 1 hour. The rate of temperature increase was set at $2^{\circ} \mathrm{C} / \mathrm{min}$, cooling to room temperature took place in the closed and disconected oven (approximately $-0.3^{\circ} \mathrm{C} / \mathrm{min}$ ). Mechanical tests were performed on control and exposed samples immediately after cooling; these tests enabled the determination of compressive and flexural strengths.

\subsubsection{Exposure to fire}

Samples, $16 \times 16 \times 4 \mathrm{~cm}^{3}$, were placed in the oven and exposed to a flame causing a temperature of $1000^{\circ} \mathrm{C}$ on the exposed face (Figure 1); this temperature was maintained for 1 hour. The outer surface of the sample remained in contact with air at ambient conditions. At the end of the test, the sample cooled under ambient conditions. Several of the samples were equipped with thermocouples to measure the temperature changes within the sample at different depths. Subsequently, to enable a comparison between the mechanical strength of samples a punching shear strength (Menetrey, 2002) test was performed as presented in Figure 2.

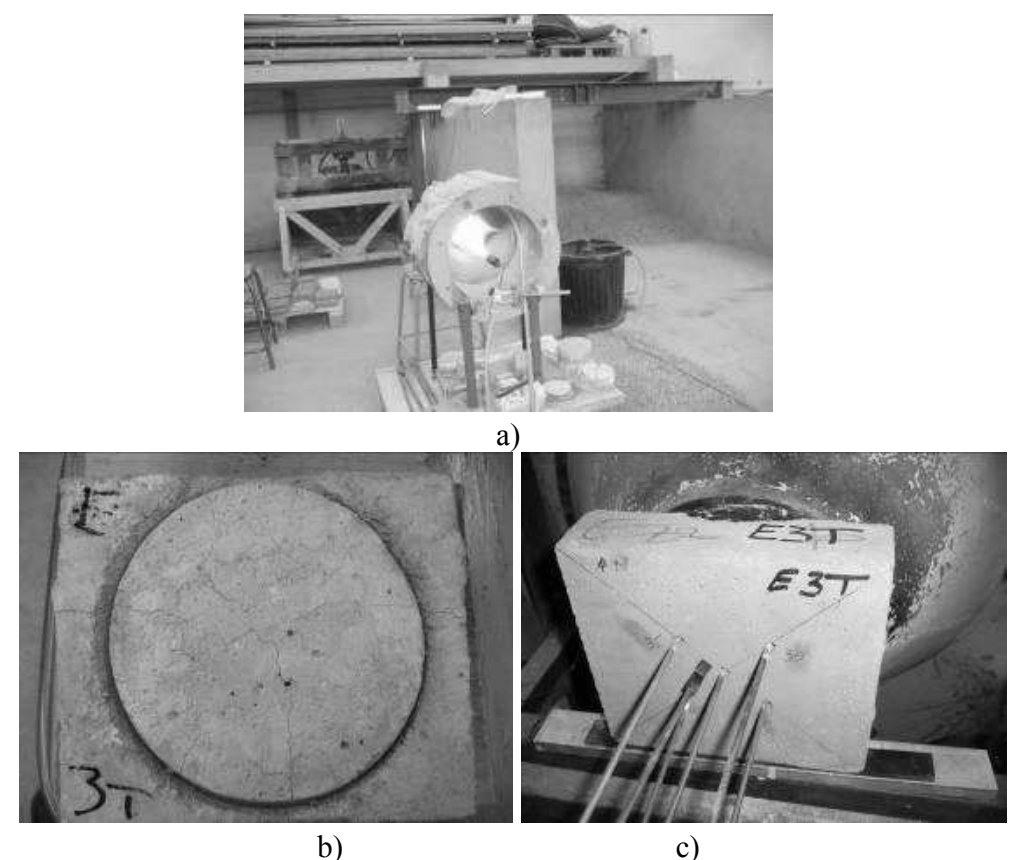

Figure 1. Fire resistance test. a) test rig; b) flame exposed surface after test; c) cold face after heat exposure 


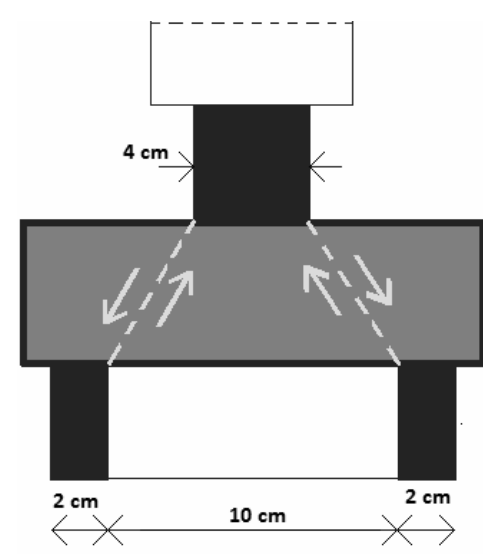

a)

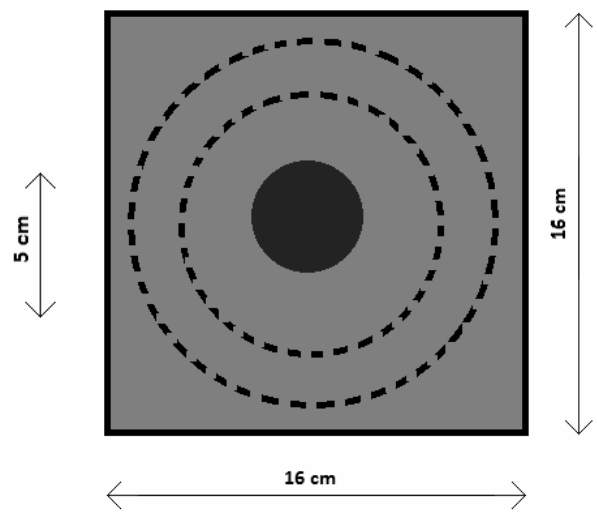

b)

Figure 2. Punching shear strength. a) test setup: the specimen is submitted to an axial load. The slab is simply supported by a circular ring; b) specimen top view

\section{Strength tests on samples not subjected to heat exposure}

\subsection{Compressive strength}

Analyses of the stress strain curves from the compression test indicate that the fibres do not contribute a significant improvement in behaviour, in either strength or elastic modulus. These observations are consistent with a number of studies (Balaguru, 1994; Rossi et al., 1996). The fibres only play a significant role after the rupture of the cement matrix. Ductility, characterized by the energy dissipated during the test, is thus substantially increased for mortars with steel fibres. At 28 days, the four mortar types have compressive strengths between 32 and $51 \mathrm{MPa}$ (Figure 2). Actually, the different mortars were water cured during 1 day only before to be exposed to $50 \%$ RH. Drying shrinkage due to this short cure and induced cracking can explain that compressive strength of the normalised mortar does not reach the expected value (above $52.5 \mathrm{MPa}$ ).

\subsection{Flexural strength}

The addition of fibres into the mortar has the most marked effect on the tensile strength. Analysis of the flexural strength results show that samples, with the addition of $0.58 \%$ by volume of steel fibres, have an increase in strength of almost $25 \%$ over the un-reinforced mortars samples. The results also show the ductile behaviour of fibre mortar. Conversely, the addition of $0.58 \%$ of polypropylene fibres tends to reduce the strength; this effect may be due to poor compaction (a stiff mix) 
during the sample preparation. The hybrid mortar $(0.29 \%$ steel fibre $+0.29 \%$ polypropylene fibres) produce flexural strengths similar to those of the standard mortar (Figure 4).

The presence of ductile fibres in the matrix significantly altered brittle behaviour by limiting rapid crack propagation and unstable failure. The presence of fibres not only slows down crack propagation with increasing load, but allows a stress transfer across (the lips) crack openings. This effect allows the composite to have a postcracking resistance and thus withstand deformations much larger than the matrix alone.

\section{Mechanical test on the mortar after heat exposure}

When exposed to high temperatures mortar suffers damage which consists of cracking and significant physicochemical changes that influence mechanical behaviour. Many authors (Georgali et al., 2005; Serdar et al., 2008; Fu et al., 2004; Fares et al., 2009) agree on the fact that strength decreases with increasing temperature of exposure.

\subsection{Compressive strength}

Figure 2 shows the evolution of the compressive strength of mortar samples, with and without fibres, in relation to the exposure temperature.

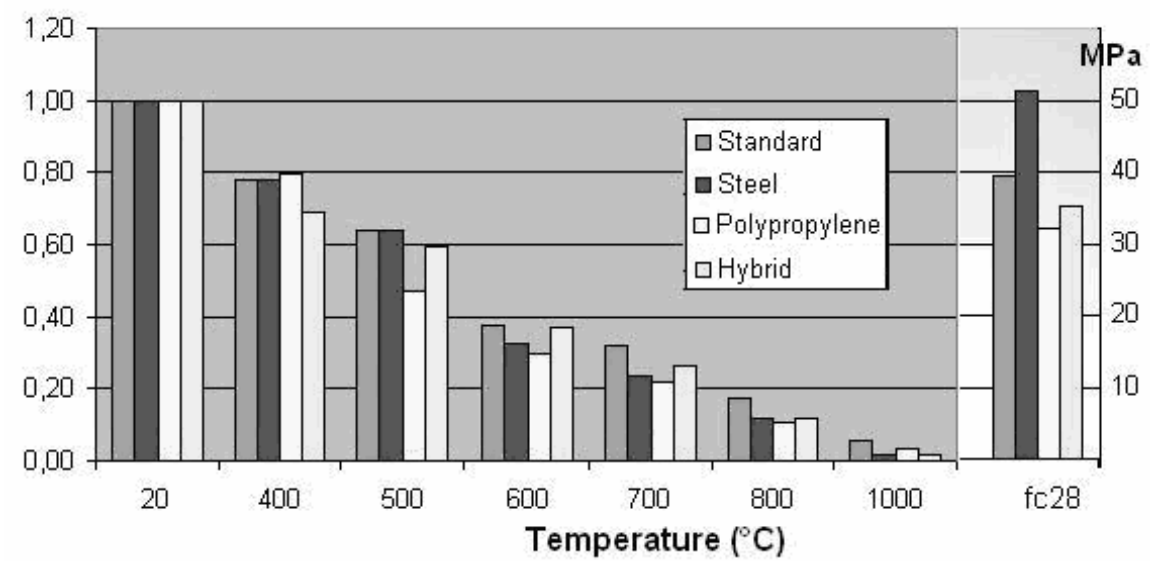

Figure 3. Evolution of compressive strength with respect to exposure temperature. The values on the left are normalised to the 28 day strength, the values to the right show the 28 day strength 
It is noted that the use of steel fibres has no effect on thermal damage for exposures between $100^{\circ} \mathrm{C}$ and $600^{\circ} \mathrm{C}$. After heat exposure at $400^{\circ} \mathrm{C}$, the compressive strength of mortar, reinforced with steel fibres is $78 \%$ of its original $20^{\circ} \mathrm{C}$ strength. The strength of normal mortar is quite similar. In excess of $600^{\circ} \mathrm{C}$, the loss of compressive strength of steel fibre mortar is higher than that of standard mortar. Therefore it is proposed that beyond this threshold, the fibres do not improve resistance to thermal damage. This difference in behaviour can be attributed to the phenomenon of scaling which is found in fibre reinforced mortars. Scaling depends on the thermal stress (the rate of temperature rise and final temperature), the shape of the sample, the fibre density and porosity of the mortar (Kanema, 2007). Figure 3 shows an example of scaling seen in steel fibre mortars at and above $800^{\circ} \mathrm{C}$. This phenomenon does not appear for non-fibred mortar.

As expected, the addition of polypropylene fibres serves to limit the thermal damage of the mortar (Xiao et al., 2006). The results presented in Figure 2 show that at $400^{\circ} \mathrm{C}$, the mortar with polypropylene fibres degrades less rapidly than the control mortar. At $170^{\circ} \mathrm{C}$, the polypropylene fibres melt and create a connecting porosity that contributes to lower vapour pressure and thus reduces cracking (Consolazio et al., 1998; Bian, 2008). However, beyond $400^{\circ} \mathrm{C}$, when all polypropylene fibres have melted, the thermal damage becomes more marked.
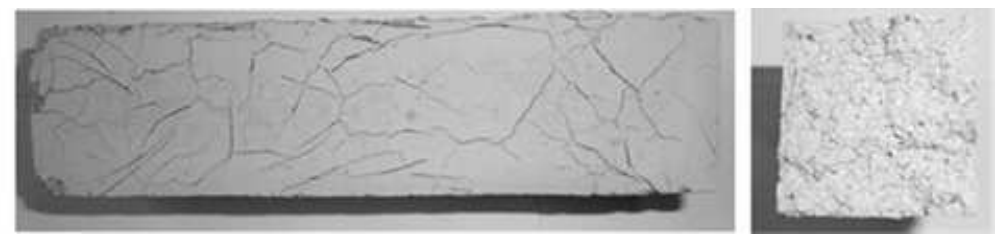

Figure 4. Example of scaling observed in a steel fibre mortar sample exposed to $1000^{\circ} \mathrm{C}$

At $400^{\circ} \mathrm{C}$, the hybrid mortar deteriorates more than the standard mortar. But, in excess of $600^{\circ} \mathrm{C}$, the hybrid mortar deteriorates as rapidly as the standard mortar. It is noted that, with respect to compressive strength, there are no positive or negative effects of adding steel and polypropylene fibres. If hybrid mortar is compared to polypropylene mortar, it is noted that the adding of steel fibres can give a better fire resistance to polypropylene mortar. Furthermore, the scaling phenomenon observed in the steel fibre mortar is greatly reduced for hybrid fibre mortar.

\subsection{Flexural strength}

Analysis of the 4 point bending flexural test results indicates that throughout the entire temperature range, the strength of steel fibre mortar is significantly greater 
than that of the standard mortar, polypropylene fibre mortar or hybrid fibre mortar (Figure 4). The thermal damage of steel fibre mortar is less than the standard mortar. In effect, the steel fibres do not limit physico-chemical changes but control thermal cracking and limit the spread of cracking during mechanical testing.

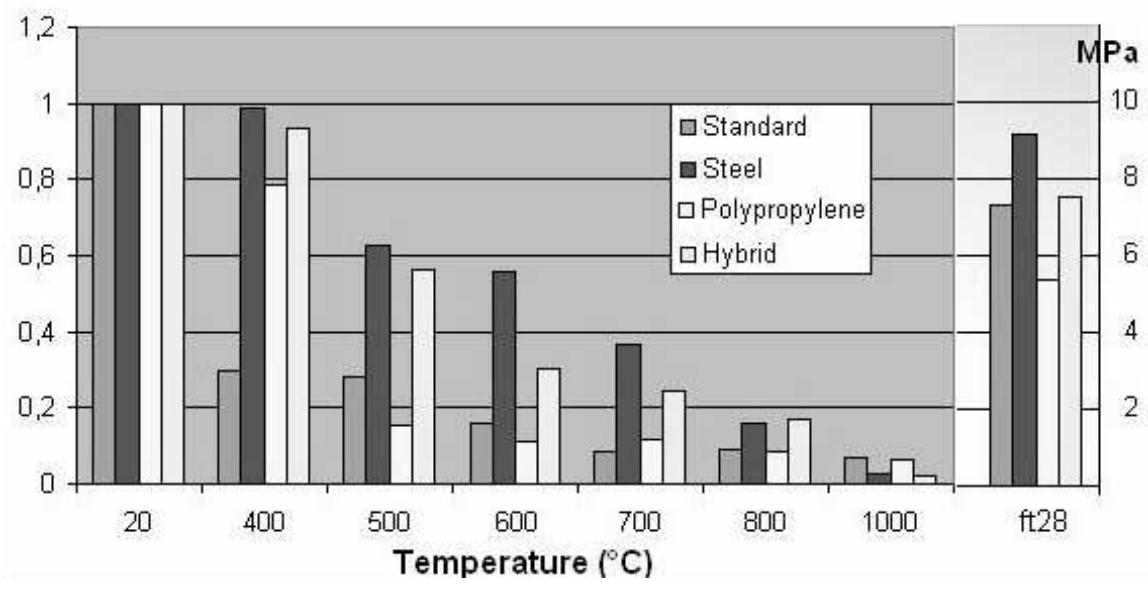

Figure 5. Evolution of flexural strength with respect to exposure temperature: the values on the left are normalised to the 28 day strength, the values to the right show the 28 day strength

As previously noted, at $400^{\circ} \mathrm{C}$, the polypropylene fibre mortar degrades less than the ordinary mortar; but in excess of $600^{\circ} \mathrm{C}$, this positive effect disappears.

The polypropylene fibres can reduce cracking by controlling the vapour pressures, but do not influence the physico-chemical changes. This suggests that the tensile strength is more sensitive to cracking than physico-chemical changes while the compressive strength is sensitive to these two phenomena.

The positive effect of polypropylene fibres also occurs in the hybrid mortar. At $400^{\circ} \mathrm{C}$, the strength of the hybrid mortar is over $90 \%$ of the initial $20^{\circ} \mathrm{C}$ strength. The thermal damage at $400^{\circ} \mathrm{C}$ is quite similar for the hybrid mortar and for the steel fibre mortar. Beyond $600^{\circ} \mathrm{C}$, deterioration of the hybrid mortar becomes more marked; only the "stitching" effect of steel fibres contributes to the strength, however this effect is weaker because the steel fibre content is lower in the hybrid mortar.

\section{Results of the flame exposure tests}

Figure 5 shows an example of temperature changes during the flame exposure test with respect to time and depth. 
The plateau at $100^{\circ} \mathrm{C}$ that is seen at the beginning of the test corresponds to the evaporation of free water at different depths. It is seen that the plateau is more prolonged the further away from the inner side (facing the flame). In this way one can quantify the propagation of heat into the mortar. Comparison of different tests indicates that there is no change in heat propagation in the presence or nature of fibres.

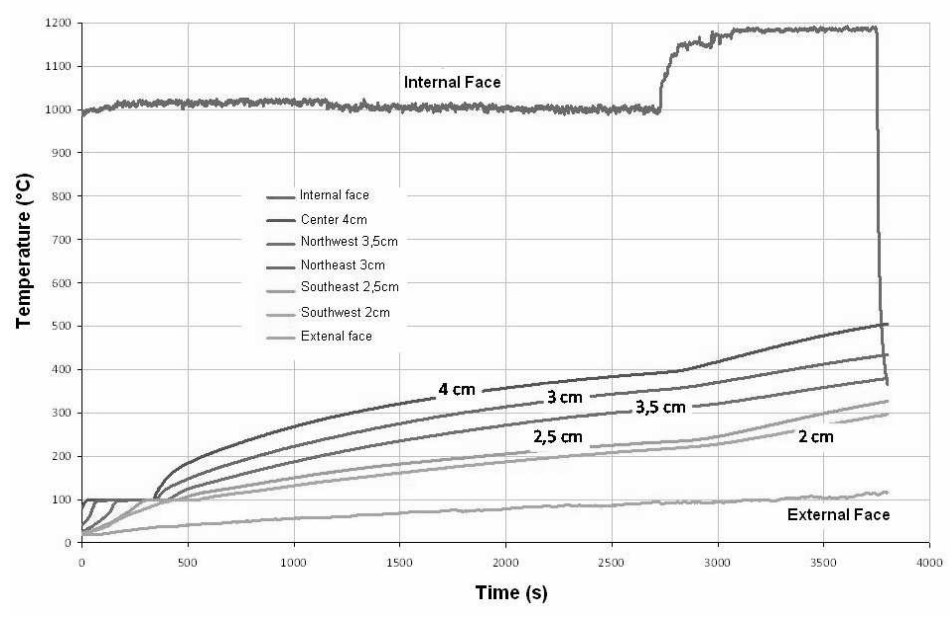

Figure 6. Evolution of temperature with respect to heat exposure time and depth within the control sample. Depths are noted from the external face (the cold face)

While the internal face of the sample is maintained at $1000^{\circ} \mathrm{C}$, temperatures inside the mortar are much lower. At the depth of $1 \mathrm{~cm}$ from the flame exposed face, the temperature did not exceed $500^{\circ} \mathrm{C}$. The "cold" face, that is to say to $5 \mathrm{~cm}$ of the flame exposed face, the temperature reached $100^{\circ} \mathrm{C}$ after 1 hour of heating. As previously noted, there is no correlation between these temperatures and the presence or nature of the fibres.

The trends observed for the compression tests and flexure are confirmed by the results of punching shear strength tests carried out after cooling. Table 1 concatenates results from heated and non heated specimens. Fibre mortars exhibit higher punching shear strength than the normal mortar as expected. After flame exposure, all mortars show a loss of punching shear strength. The thermal damage of steel fibre mortar is less than the normal mortar. The punching shear strength of mortar, reinforced with steel fibres is $72 \%$ of its original $20^{\circ} \mathrm{C}$ strength. The normal mortar residual strength is less than 20\%. Polypropylene and hybrid mortars give an intermediate behaviour (Figure 7). 
Table 1. Maximum punching load for samples exposed to flame.

\begin{tabular}{|l|c|c|c|c|}
\hline $\mathbf{F}_{\max }(\mathbf{k N})$ & Normal & Steel & Polypropylene & Hybrid \\
\hline Not heated & 27,5 & 40 & 33 & 37 \\
\hline Heated & 5 & 28,7 & 10,3 & 14,4 \\
\hline
\end{tabular}

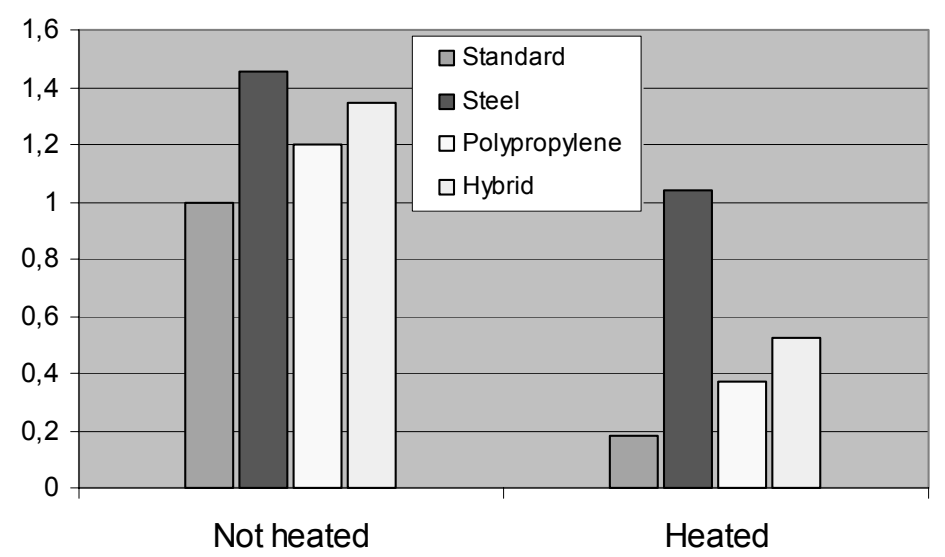

Figure 7. Comparison of the punching shear strengths of heated and non heated mortars. The values are normalised to normal mortar strength at $20^{\circ} \mathrm{C}$

\section{SEM observations}

The physico-chemical degradation of cementitious materials due to high temperatures has been investigated by several authors (Castellote et al., 2004) (Georgali et al., 2005). The present study focuses on changes in metal fibres; the polypropylene fibres, which melt at $170^{\circ} \mathrm{C}$, were not observed in this study.

Observation under a scanning electron microscope and microprobe analysis indicate that up to $400^{\circ} \mathrm{C}$ (Figure 6b), there is good adhesion between the cement paste and the fibre. It is noted that there is a deposit on the fibre consisting of $\mathrm{Ca}, \mathrm{O}$, $\mathrm{Si}$ and $\mathrm{Al}$ from the cement hydrates. At $800^{\circ} \mathrm{C}$ (Figure $6 \mathrm{c}$ ), there is a debonding of the cement matrix as well as cracks on the fibre surface. The microprobe analysis of these cracks shows a strong composition of $\mathrm{Fe}$ and $\mathrm{O}$, which suggests hightemperature oxidation of steel. At $1000^{\circ} \mathrm{C}$ the phenomenon is further accentuated. A zoom on the surface of the fibre (Figure 7) shows the presence of "soft" formations. Vourlias et al. (2008) have observed similar formations on steel heated to $950^{\circ} \mathrm{C}$ for 15h. This high-temperature oxidation explains the significant loss of strength and ductility of steel fibre reinforced mortar steel above $800^{\circ} \mathrm{C}$. 
(a)

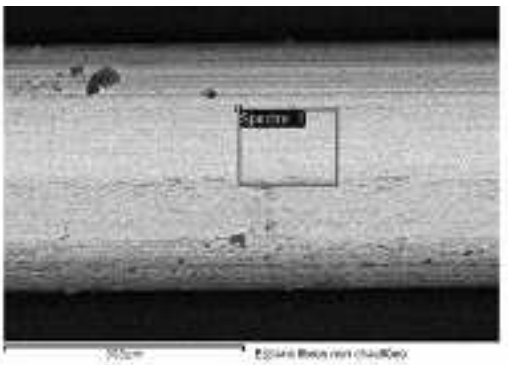

(c)

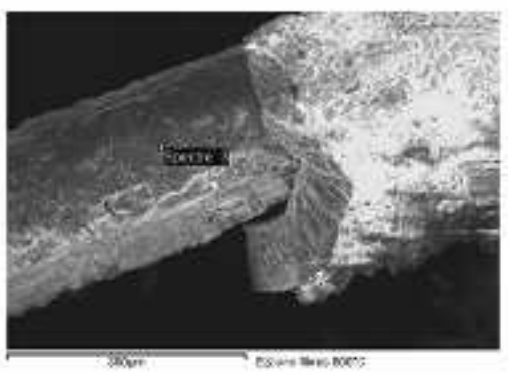

(b)

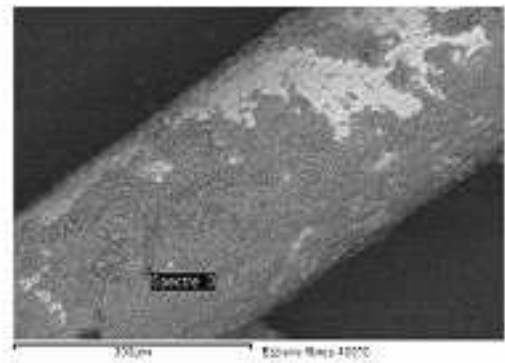

(d)

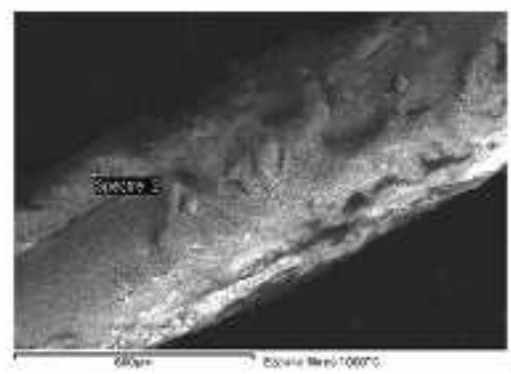

Figure 8. SEM observations (scale $300 \mu \mathrm{m}$ ) of steel fibres extracted from samples exposed to (a) ambient conditions (b) $400^{\circ} \mathrm{C}$ (c) $800^{\circ} \mathrm{C}$ and (d) $1000^{\circ} \mathrm{C}$

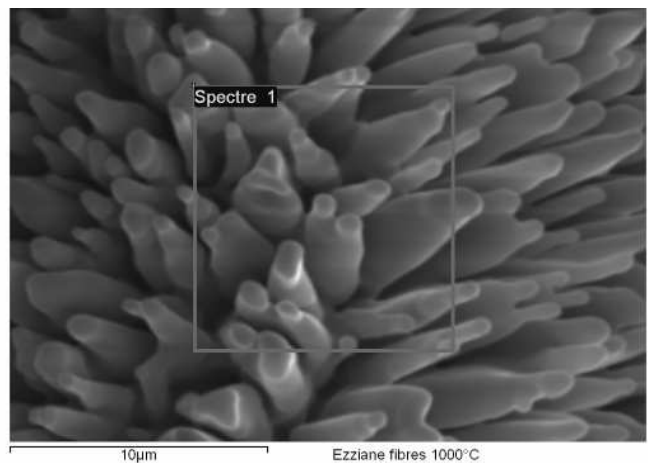

Figure 9. Observation of oxides formed on the surface of steel fibres taken from a sample exposed to $1000^{\circ} \mathrm{C}$

\section{Conclusions}

In this paper, a study has been made of the mechanical behaviour of standard mortars, steel fibre mortar, polypropylene fibre mortar and a hybrid mortar, subjected to thermal exposure at $400^{\circ} \mathrm{C}, 600^{\circ} \mathrm{C}, 800^{\circ} \mathrm{C}$ and $1000^{\circ} \mathrm{C}$. Two types of 
heat exposure have been carried out: slow heating in an oven and rapid heating due to exposure to a flame.

The results show that steel fibres can limit the damage of mortars during exposure to heat. Even if the steel fibres do not alter physico-chemical deterioration, they limit cracking during exposure to heat, and control the spread of these cracks during mechanical loading.

The fibres of polypropylene melt at $170^{\circ} \mathrm{C}$ thus creating a porosity which limits pore pressure due to evaporation of pore water that occurs during heat exposure; consequently cracking is reduced during exposure to heat.

The hybrid mortars appear to offer a good compromise: the polypropylene fibres reduce internal pressure that causes cracking during heat exposure and steel fibres limit cracking during the heat exposure and under subsequent mechanical loading. The SEM observations and microprobe analysis show oxidation of steel fibres at high temperatures. This oxidation causes a loss of strength and ductility above $800^{\circ} \mathrm{C}$. This effect may limit the advantages of adding steel fibres, for example, with respect to enhancing the safety of structures at risk from fire damage.

\section{References}

Andrade C., Sarría J., Alonso C., "Relative humidity in the interior of concrete exposed to natural and artificial weathering", Cement and Concrete Research, vol. 29, 1999, p. 1249-1259.

Balaguru P., "Fiber reinforced concrete for structural components. A state of art", Workshop on Fiber Reinforced Cement \& Concrete, Sheffield, U.K., July 1994.

Bian H., Etude expérimentale de l'endommagement de BFUHP sous sollicitations physique, chimique et mécanique, Thèse de doctorat, INSA de Rennes, 2009.

Castellote M., Alonso C., Andrade C., Turrillas X., Campo J., "Composition and microstructural changes of cement pastes upon heating, as studied by neutron diffraction", Cement and Concrete Research, vol. 34, 2004, p. 1633-1644.

Consolazio G.R., McVay M.C., Rish III J.W., "Measurement and prediction of pore pressures in saturated cement mortar subjected to radiant heating", ACI Material Journal, vol. 95, 1998 , p. $525-536$

Fares H., Noumowe A., Remond S., "Self-consolidating concrete subjected to high temperature. Mechanical and physicochemical properties", Cement and Concrete Research, vol. 39, 2009, p. 1230-1238.

Fu Y.F., Wong Y.L., Poon C.S., Tang C.A., Lin P., "Experimental study of micro/macro crack development and stress-strain relations of cement-based composite materials at elevated temperatures", Cement and Concrete Research, vol. 33, 2004, p. 789-797.

Georgali B., Tsakiridis P. E., "Microstructure of fire-damaged concrete. A case study", Cement and Concrete Composites, vol. 27, 2005, p. 255-259. 
Kanema M., Influence des paramètres de formulation et microstructuraux sur le comportement à haute température des bétons, Thèse de doctorat, université de CergyPontoise, 2007.

Menétrey Ph., "Synthesis of punching failure in reinforced concrete", Cement and Concrete Research, vol. 24, 2002, p. 497-507.

Rossi P., Ulm F.-J., Hachi F., "Compressive behavior of concrete: physical mechanisms and modelling", Journal of Engineering Mechanics, ASCE, vol. 122, n 11, 1996, p. 1038-1043.

Serdar A., Halit Y., Bulent B., "High temperature resistance of normal strength and autoclaved high strength mortars incorporated polypropylene and steel fibers", Construction and Building Materials, vol. 22, 2008, p. 504-512.

Vourlias G., Pistofidis N., Chrissafis K., "High-temperature oxidation of precipitation hardening steel", Thermochimica Acta, vol. 478, n 1-2, 2008, p. 28-33.

Xiao J., Falkner H., "On residual strength of high-performance concrete with and without polypropylene fibres at elevated temperatures", Fire Safety Journal, vol. 41, 2006, p. 115-121. 